Article

\title{
Narcissism and Self-Esteem as Correlates of Secondary School Students' Mathematics Academic Achievement in Anambra State
}

\author{
Adeline N. Anyanwu 1(D, Ngozi E. Ezenwosu ${ }^{1}$, Kingsley E. Emesi ${ }^{2}$, Lydia I. Eleje ${ }^{3}{ }^{*}(\mathbb{D}$ \\ ${ }^{1}$ Curriculum Unit, Department of Educational Foundations, Nnamdi Azikiwe University, Awka, Nigeria \\ ${ }^{2}$ Department of Educational Foundations Faculty of Education, Nnamdi Azikiwe University Awka Anambra \\ State, Nigeria \\ ${ }^{3}$ Evaluation, Research and Statistics Unit, Department of Educational Foundations, Faculty of Education, \\ Nnamdi Azikiwe University, Awka Anambra State, Nigeria \\ *Correspondence: ijeomaexcite@gmail.com
}

How to cite this paper: Anyanwu, A. N., Ezenwosu, E. N., Emesi, K. E., \& Eleje, L. I. (2022). Narcissism and Self-Esteem as Correlates of Secondary School Students' Mathematics Academic Achievement in Anambra State. Open Journal of Educational Research, 2(1), 13-22. Retrieved from https://www.scipublications.com/journal/index.php/ojer/article/view/200

Received: December 12, 2021 Accepted: February 21, 2022 Published: February 22, 2022

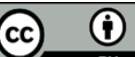

Copyright: (C) 2022 by the authors. Submitted for possible open access publication under the terms and conditions of the Creative Commons Attribution (CC BY) license (http://creativecommons.org/licenses /by/4.0/).

\begin{abstract}
The impact of narcissism and self-esteem on academic achievement has long been an important issue in developmental research. The study aimed to explore the students' narcissism and self-esteem as correlates of academic achievement in Mathematics in Anambra State. Five research questions and five null hypotheses guided the study. The study adopted a correlational approach. The population of the study comprised of 21204 SS2 students from which a sample of 630 was drawn. Multi-stage procedure was used to select the sample. Two standardized research instruments namely; Narcissistic Personality Inventory (NPI), and Self-esteem Questionnaire (SQ), as well as score from students' promotional examination were used for data collection. Cronbach's alpha was used to determine the reliability of the items in the instruments. The overall reliability coefficient was 0.75 which shows that the instrument was reliable and good for the study. The Pearson Product Moment Correlation was used to answer research questions 1 to 4 and to test hypotheses 1 to 4 , while the research question 5 and hypothesis 5 were answered and tested with multiple correlations. The findings showed that students' power narcissism recorded a very low positive relationship with academic achievement in mathematics. Findings also revealed that the multiple correlation of these variables is positively non significant with academic achievement in mathematics. Based on these findings, it was recommended that as narcissistic individuals believe strongly that they are better than others, teachers and counsellors should develop a strategy to enhance the confidence and ability in the students as these will help them to become life long learning individuals thereafter.
\end{abstract}

Keywords: Narcissism, Self-esteem, Academic achievement, Mathematics, Secondary school

\section{Introduction}

In determining narcissism as another anti-social behaviour which may likely lead to violence experience on individuals in the society has social imperative in the field of developmental psychology. Narcissism is characterized by dissociation between an unconscious sense of inadequacy and a conscious feeling of superiority. According to Miller and Campbell (2008)[1] narcissism did not emerge as a mental disease until the appearance of the book Diagnostic and Statistical Manual of Mental Disorders (DSM-in) published by American Psychiatric Association. On this note, American Psychiatric Association (2007) as cited by Lima, Cunha, and Avelino (2018)[2] defined narcissistic personality disorder as a grandiose sense of self-importance or uniqueness, preoccupation with fantasies of constant attention and admiration, characteristic disturbances in interpersonal relationships, such as feelings of entitlement, interpersonal exploitativeness, relationship that alternate between extreme of over-individualization and devaluation, and lack of empathy. On the 
other hand, Seto (2012)[3] observed that narcissism is a psychological condition defined as a total obsession with self, to the exclusion of almost all other interaction with people. Also, Doty and Fenlason (2013)[4] noted that narcissism is an inflated sense of self-importance and it is an extreme preoccupation of self. This concept has been extended beyond the confines of mental disease to include other tendencies, which can be differentiated into clinical and subclinical (non-pathological). While clinical narcissism is defined as a personality disorder, subclinical narcissism can be understood as a personality characteristic or trait, presented by many individuals who are considered to be normal.

The present study will specifically examine narcissistic trait or non-pathological narcissism in relation with self-esteem to understand how these variables could jointly relate to academic achievement. For example, in exploring the narcissistic trait, Doty and Fenlason (2013)[4] discovered that narcissistic students were more likely to view their academic skill as fully developed, and they were more comfortable relying on their gut instinct. These scholars insisted that narcissistic students were also more confident within a classroom of peers, more comfortable in asking question in the class and more willing to engage with teachers. The scholars reported that these set of students are wiling to skip class, ask for extension, blame professors for poor grades, and strategically compliment professors. Also, Ballard (2018)[5] noted that the characteristics of narcissistic students are probably well-aligned with the realities of the academic reward structure. That is they use comer-cutting facilities in maintaining grades without high effort.

In interpersonal contexts, narcissistic traits serve as a mechanism for self-regulation, in which motivations, relationships with others, and self-regulation strategies interact, leading to narcissistic behaviour (Campbell, Hoffman, Campbell \& Marchision, 2011)[6]. Individuals with excessively narcissistic traits tend to show a strong sense of self-importance (Brown, Budzek, \& Tamborski, 2009)[7], or a strong sense of entitlement, characterized by a general feeling that they deserve more rewards and recognition than others (Campbell, Bxline, \& Bushman, 2004)[8]. According to these scholars, people in these categories see themselves to be more positive than their peers and believe they are better than others and strongly depend on positive feed back from others. If this feed back is not obtained, such as in the case of failure, the narcissist responds with extreme expression of negative emotion (Lima, Avelino, \& Cunha, 2018)[2]. In discussing the attributes of narcissistic individuals, Hudson (2012)[9] observed that narcissistic behaviour is a term used to describe or label someone that is self-centered.

Essentially, Doty and Fenlason (2013)[4] suggest that a possible increase in narcissistic personality tendencies among secondary school students has a very real and serious impact on the society. Therefore, examining the concept of narcissism and its detrimental link to self-esteem as a contiguous construct in human being has social and cognitive implication in relating to academic achievement in the Nigerian academic endeavour. This is because narcissistic tendency may provide individual of low self-esteem with an increase sense of inferiority dependence, while narcissistic tendency may also provide individual of high self-esteem with an increase sense of superiority and independence, as narcissism and high self-esteem are representing the inflated self of an individual. The interaction between these constructs will then help to understand the impact of these constructs on students' academic achievement. The problem that arises from this reality is that narcissistic traits among students can be associated with difficulties such as reactions to criticism towards the individual's inflated self. Beside this, narcissists in the academic setting tend to consider their performance when it is moderately and fairly good as not acceptable to the standard of excellence which is their anticipated grade (Wallace \& Baumeister, 2002)[10]. As indicated by Hudson, future leaders preponderantly emerge from the ranks of college students, and narcissism is harmful not only to their performance by posing obstacle to learning but to society as a whole. Thus people with narcissism are constantly concerned and motivated to maintain the inflated self-esteem through a variety of intrapersonal and interpersonal mechanisms. Hudson further stated that it is important 
to note that individuals that are high in narcissistic traits encounter many problems including difficulties with interpersonal and professional relationships, and poor insight and self-awareness.

In this study, the construct of narcissism will be examine in two clusters such as powers and exhibitionism as these had covered the characteristics of narcissism such as; authority, superiority, entitlement, exploitativeness, self-sufficiency and vanity (Raskin \& Hall, 1979)[11]. The authority and self-sufficiency factors are referred to as adaptive narcissistic factors that characterized power and exhibitionism types of narcissism because of their association with desirable personality variables, whereas the exploitativeness and entitlement factors are referred to as maladaptive factors because of their associations with less desirable personality variables (Soyer, Kopelman, \& Waston, 2001)[12]. Since the above scholarly review had noted that narcissism can influence the inflated self of an individual, examining their impact in determining the development of self-esteem is one of the aims of the present study. Therefore, the present study will assess narcissism to negate the possibility that unrealistically self-esteem is related to narcissism.

Suffice it to say that Campbell, et al, (2011)[6] suggested that narcissism may provide individuals with low self-esteem with an increased sense of power and independence. Also, that narcissism may serve as attention seeking behaviour which enhances self-esteem, or that individuals with low self-esteem may externalize blame for their problems and failures to protect themselves against feelings of inadequacy, inferiority, and shame, which leads to narcissistic behaviour towards others. Therefore, understanding self-esteem from the study of Baumeister (1998)[13] has defined it as the evaluative aspect of the self-concept that corresponds to an overall view of the self as worthy or unworthy. That is, a personal judgement of the worthiness that is expressed in the attitudes the individual holds towards his/her self. Thus, self-esteem is an attitude about the self and is related to personal beliefs about skills, abilities, social relationships, and future outcomes. Self-esteem is produced over the life and can be either positive (high self-esteem) which resulted to positive outcomes or negative (low self-esteem) which resulted to negative outcomes (Saadat, Ghasezadch \& Soleimani, 2012)[14].

High self-esteem means that a person has a conviction to do what is right in life. Low self-esteem has been defined a belief that represents individual's negative emotion towards the self which embraces negative appraisal by lowering his/her self-view (Ghazvini, 2011)[15]. The effects of self-esteem in students' life is so crucial that those with high selfesteem are more likely to persist in the face of difficulties and are better equipped in their personal lives to cope with challenges that arise unlike those with low self-esteem (Anyamene, Nwokolo \& Ezeani, 2016)[16]. Also, high self-esteem individuals may be more likely to take steps to restore a damaged self-view than low self-esteem individuals.

However, there are relatively little research evidences on whether self-esteem can relate with narcissism or whether narcissism and self-esteem can jointly relate with academic achievement. Thus this is to support the claim that narcissistic individuals are prone to defending their high self-esteem. The study of Papageorgiou, Malanchini, Denovan, Clough, Shakeshaft, Schofield, and Kovas (2018)[17] reported that narcissism did not correlate significantly with school achievement. The study of Zainal (2020)[18] reported a significant relationship between narcissism and students' academic performance. The study of Donnellan Trzesniewski, Robins, Moffitt and Caspi (2005)[19] reveals that selfesteem and narcissism were moderately related. The study of Anyanwu and Emesi (2020)[20] reported a very low positive and significant relationship between the two dimensions of self-esteem and academic achievement. In another study conducted by Anyanwu and Emesi (2020)[20], it reported that students' self-esteem recorded a very low negative relationship with academic achievement in mathematics. Arshad, Zaidi and Mahmood (2015)[21] also recorded that there was a significant relationship between selfesteem and academic performance. With the foregoing observations the present study will make an attempt to examine the possibility of how students' self-esteem and narcissism 
jointly relate to determine academic achievement. No known study has revealed the relationship that existed between narcissism and students' academic achievement and this is one of the gaps in the knowledge which the present study sought to cover.

Academic achievement has been defined as scores obtained from examination that measure the extent to which a person has acquired certain information or mastered certain skills, usually as a result of specific instruction (Eleje et al., 2020a)[22]. It is assumed that the perceptions of students toward their narcissism that include adaptive and maladaptive behaviour in connection with their self-esteem will have robust relative indicators towards their academic achievement. On this note, the study will adopt students' promotion mathematics scores to represent academic achievement.

For students to learn and achieve excellently, especially in the subject that deals with articulation and aggregation, they must be sufficiently and psychologically healthy in behavior (Eleje et al., 2020) [23]. A psychologically healthy individual is the person that has a positive perception of his/her behaviour as it represents the total self. This positive personality view can be developed through educational processes in the formal educational institutions. Surprisingly, the dramatic increase in the prevalence of problematic behaviours during adolescence has broken the traditional view that academic success is the only standard in assessing good students. In the Nigerian settings, not only students' academic achievement, but also their behaviour has been given considerable public attention. For example, Masten, Rosiman, Long, Burt, Obrandovic \& Riley (2005)[24] proposed that for school-age children, high academic achievement and behavioural competence should be regarded as two important indicators for their success. It has been observed that narcissist behaviours are triggered by the size of the individual's social network, relations with peers, and efficiency in social skills. These could have social implications to determine individuals' narcissism which may relate negatively with self-esteem as well as their academic achievement.

Therefore, to explore the relationship of students' narcissism, and self-esteem as correlate of their academic achievement has social imperative for developing effective intervention programs within the school environments. Stemming from the aforementioned literature, the present study aimed to fill the void of empirical paucity pertaining to the students' narcissism and self-esteem as correlate of academic achievement in Anambra State.

\subsection{Research Questions}

1. What is the relationship between students' narcissism and their academic achievement in mathematics?

2. What is the relationship between students' self-esteem and their academic achievement in mathematics?

3. What is the relationship between students' high self-esteem and their narcissism?

4. What is the relationship between students' low self-esteem and their narcissism?

5. What is the nature of relationship among students' narcissism, self-esteem and their academic achievement in mathematics?

\subsection{Hypotheses}

1. There is no significant relationship between students' narcissism and their academic achievement in mathematics.

2. There is no significant relationship between students' self-esteem and their academic achievement in mathematics.

3. There is no significant relationship between students' high self-esteem and their narcissism.

4. There is no significant relationship between students' low self-esteem and their narcissism. 
5. The nature of relationship among students' narcissism, self-esteem and their academic achievement in mathematics is not significant.

\section{Method}

The researchers used a correlational research design and questionnaires to collect data for the study. The population of this study consisted of 21204 being the total number of students in senior secondary school class II in Anambra State. A sample size of 630 questionnaires were administered to respondents and collected for data analysis. Out of the 630 questionnaires administered to the respondents, 609 of them were found useful during data analysis. Multi-stage sampling procedure was used to select the respondents. The procedures for the selection were as follows: In stage one, three education zones were selected from the six education zones in the state by simple random sampling. Then in stage two, from each sampled education zone, one local government area (L.G.A) was selected through simple random sampling given a total of three (3) L.G.As. In stage three, from each sampled L.G.A, ten (10) schools were randomly selected giving a total of thirty (30) schools. Then, from each of the schools, 21 SSII students were selected for the study using a table of simple random sampling. This gave a total number of 630 students used in the study.

The study adapted two standardized research questionnaires namely, Raskin and Hall (1979)[11] Narcissistic Personality Inventory (NPI), and Eysenck and Eysenck Selfesteem Questionnaire (1976)[25]. The students' achievement scores in Mathematics from the state wide senior secondary one (SS1) promotion examination were obtained from the schools before the administration of the instruments.

The methods used for validating the instruments were face and construct validity by three experts from the Faculty of Education, Nnamdi Azikiwe University Awka. Cronbach's alpha reliability method was used to determine the internal consistency of the items in the research instruments such as; 0.69 , for power, 0,70 , for exhibitionism, 0.83 , for high self-esteem and 0.76 for low self-esteem respectively. The overall reliability coefficient was 0.75 which shows that the instrument was reliable and good for the study. According to guide lines by Haradhan, (2017)[26], a coefficient of (0.6 is considered to be poor), 0.7 is acceptable while over 0.8 is good. The Pearson Product Moment Correlation Coefficient was used in answering research questions one to four and testing of hypotheses one to four. Multiple correlations were used to answer research question five and to test hypothesis five at 0.05 level of significance. The decision rule is that null hypotheses with P-value higher than 0.05 was not rejected, while the hypotheses with P-value lower than 0.05 was rejected. The rough guide developed by Okoye (2015)[27] was adopted for guide and interpretation of correlation coefficient result values when a large number of pairs of scores have been correlated. The decision rules to interpret the research questions were presented as follows: $r=.00$, no relationship; $r= \pm 0.0$ to \pm 0.2 , very low relationship; $\mathrm{r}= \pm 0.2$ to \pm 0.4 , low relationship; $\mathrm{r}= \pm 0.4$ to \pm 0.6 , medium relationship; $\mathrm{r}= \pm 0.6$ to \pm 0.8 , high relationship; and $\mathrm{r}= \pm 0.8$ to \pm 1.0 , very high relationship.

\section{Presentation of Results}

Research Question 1: What is the relationship between students' narcissism and their academic achievement in mathematics?

Table 1. The Relationship between Students' Narcissism and their Academic Achievement in Mathematics

\begin{tabular}{ccc}
\hline Variables & Academic achievement (r) & Remarks \\
\hline Power narcissism & .061 & very low positive relationship \\
Exhibitionism narcissism & -.039 & very low negative relationship \\
\hline
\end{tabular}


The result in Table 1 reveals a very low positive relationship between students' power narcissism and their academic achievement in mathematics. A very low negative relationship was recorded between students' exhibitionism narcissism and their academic achievement in mathematics.

Research Question 2: What is the relationship between students' self-esteem and their academic achievement in mathematics?

Table 2. The Relationship between Students' Self-Esteem and their Academic Achievement in Mathematics

\begin{tabular}{ccc}
\hline Variables & Academic achievement (r) & Remarks \\
\hline High self-esteem & .007 & very low positive relationship \\
Low self-esteem & .017 & very low positive relationship \\
\hline
\end{tabular}

$(N=626)$

The result in Table 2 reveals a very low positive relationship between students' high self-esteem and their academic achievement in mathematics. A very low positive relationship was recorded between students' low self-esteem and their academic achievement in mathematics.

Research Question 3: What is the relationship between students' high self-esteem and their narcissism?

Table 3. Relationship between Students' Narcissism and Their High Self-Esteem

\begin{tabular}{ccc}
\hline Variables & High self-esteem (r) & Remarks \\
\hline Power narcissism & .021 & very low positive relationship \\
Exhibitionism narcissism & -.038 & very low negative relationship \\
\hline
\end{tabular}

$(N=626)$

The result in Table 3 reveals a very low positive relationship between students' power narcissism and their high self-esteem. A very low negative relationship was recorded between students' exhibitionism narcissism and their high self-esteem.

Research Question 4: What is the relationship between students' low self-esteem and their narcissism?

Table 4. Relationship between Students' Narcissism and Their Low Self-Esteem

\begin{tabular}{ccc}
\hline Variables & Low self-esteem (r) & Remarks \\
\hline Power narcissism & .062 & very low positive relationship \\
Exhibitionism narcissism & -.036 & very low negative relationship \\
\hline
\end{tabular}

$(N=626)$

The result in Table 4 reveals a very low positive relationship between students' power narcissism and their low self-esteem. A very low negative relationship was recorded between students' exhibitionism narcissism and their low self-esteem.

Research Question 5: What is the nature of relationship among students' narcissism, self-esteem and academic achievement in mathematics?

Table 5. The Relationship among Students' Narcissism, Self-Esteem and Academic Achievement in Mathematics

\begin{tabular}{ccccc}
\hline Model & $\mathbf{R}$ & R Square & Adjusted R Square & Std. Error of the Estimate \\
\hline 1 & $.071^{\mathrm{a}}$ & .005 & .000 & 6.97961 \\
\hline
\end{tabular}


Table 5 reveals that the relationship among students' narcissism, self-esteem and academic achievement is very low at $0.71^{\text {a }}$, while the standard error of estimate is 6.97961 .

Hypothesis 1: There is no significant relationship between students' narcissism and their academic achievement in mathematics.

Table 6. Relationship between Students' Narcissism and Academic Achievement in Mathematics

\begin{tabular}{cccc}
\hline Variable & Mathematics achievement (r) & P-value & Remark \\
\hline Power narcissism & .061 & .129 & NS \\
Exhibitionism narcissism & -.039 & .327 & NS \\
\hline
\end{tabular}

$(N=626)$ NS-Non-Significant correlation at 0.05 level of significance.

The results in Table 6 reveals that there is a non significant relationship between students' power narcissism and their academic achievement in mathematics $(r=.061>0.05)$. There is a non significant relationship between students' exhibitionism narcissism and their academic achievement in mathematics $(r=-.039>0.05)$.

Hypothesis 2: There is no significant relationship between students' self-esteem and their academic achievement in mathematics.

Table 7. Relationship between Students' Self-Esteem and Academic Achievement in Mathematics

\begin{tabular}{cccc}
\hline Variable & Mathematics achievement (r) & P-value & Remark \\
\hline High self-esteem & .007 & .861 & NS \\
Low self-esteem & .017 & .665 & NS \\
\hline
\end{tabular}

$(\mathrm{N}=626)$ NS-Non-Significant correlation at 0.05 level of significance.

The results in Table 7 reveals that there is a non significant relationship between students' high self-esteem and their academic achievement in mathematics $(r=.007>0.05)$. There is a non significant relationship between students' low self-esteem and their academic achievement in mathematics $(r=.017>0.05)$.

Hypothesis 3: There is no significant relationship between students' high self-esteem and their narcissism.

Table 8. Relationship between Students' High Self-Esteem and Academic Achievement in Mathematics

\begin{tabular}{cccc}
\hline Variable & High self-esteem $(\mathbf{r})$ & P-value & Remark \\
\hline Power narcissism & .021 & .608 & NS \\
Exhibitionism narcissism & -.038 & .346 & NS \\
\hline
\end{tabular}

NS-Non-Significant correlation at 0.05 level of significance.

The results in Table 8 reveals that there is a non significant relationship between students' high self-esteem and their power narcissism $(r=.021>0.05)$. There is a non significant relationship between students' high self-esteem and their exhibitionism narcissism ( $\mathrm{r}$ $=-.038>0.05)$.

Hypothesis 4: There is no significant relationship between students' low self-esteem and their academic narcissism.

Table 9. Relationship between Students' Low Self-Esteem and Academic Achievement in Mathematics

\begin{tabular}{cccc}
\hline Variable & Low self-esteem $(\mathbf{r})$ & P-value & Remark \\
\hline Power narcissism & .062 & .062 & NS \\
Exhibitionism narcissism & -.036 & .372 & NS \\
\hline
\end{tabular}

$(N=626)$ NS-Non-Significant correlation at 0.05 level of significance. 
The results in (Table 9 reveals that there is a non significant relationship between students' low self-esteem and their power narcissism $(r=.062>0.05)$. There is a non significant relationship between students' low self-esteem and their exhibitionism narcissism $(\mathrm{r}=-.036>0.05)$.

Hypothesis 5: Multiple Correlations of Students' Narcissism, Self-esteem and Academic Achievement in Mathematics.

Table 10. The Results of Multiple Correlations

\begin{tabular}{c|c|c|c|c|c|c|c|c|c}
\hline Model & $\mathrm{R}$ & R Square & $\begin{array}{c}\text { Adjusted R } \\
\text { Square }\end{array}$ & & $\begin{array}{c}\text { Std. Error of } \\
\text { the Estimate }\end{array}$ & & & \multicolumn{4}{|c}{ Change Statistics } \\
\cline { 3 - 9 } & & & & & $\begin{array}{c}\text { R. Square } \\
\text { Change }\end{array}$ & F.Change & df1 & df2 & Sig.F Change \\
\hline 1 & $.071^{\mathrm{a}}$ & .005 & .000 & 6.47961 & .005 & 1.047 & 3 & 622 & .371 \\
\hline
\end{tabular}

The Table 100 shows a multiple correlation run to examine the relationship among students' narcissism, self-esteem and academic achievement. The result in the table also reveals that the relationship among these variables is positively non significant with academic achievement in mathematics $(r=.071>.371)$. Therefore, the null hypothesis was accepted as it was concluded that the relationship among students' aggression, narcissism and academic achievement is positively and non-significantly related with one another.

\section{Discussion of findings}

The findings from table one revealed a very low positive relationship between students' power narcissism and their academic achievement in mathematics. A very low negative relationship was recorded between students' exhibitionism narcissism and their academic achievement in mathematics. The results from the hypothesis of this reveals that power narcissism and exhibitionism narcissism did not correlate significantly with academic achievement in mathematics This supported the study of Papageorgiou, et al (2018)[17] which reveals that narcissism did not correlate significantly with school achievement. These findings did not support the study of Zainal (2020)[18] which recorded a significant relationship between narcissism and academic performance.

The findings from table two revealed a very low positive relationship between students' high self-esteem and their academic achievement in mathematics. A very low positive relationship was recorded between students' low self-esteem and their academic achievement in mathematics. These supported the studies of Anyanwu and Emesi (2020a, $\& 2020 b)[20,28]$ which recorded a very low positive relationship between the two dimensions of self-esteem and academic achievement in mathematics. The results from the hypothesis of this revealed that there is a non-significant relationship between the two dimensions of self-esteem and academic achievement in mathematics. There is a non significant relationship between students' low self-esteem and their academic achievement in mathematics. These does support the studies of Anyanwu and Emesi (2020a, \& 2020b) $[20,28]$ which recorded a significant relationship between the two dimensions of self-esteem and students' academic achievement in mathematics. These results also do not support the study of Arshad, Zaidi and Mahmood (2015)[21] which recorded that there was a significant relationship between self-esteem and academic performance.

The findings from table three and four revealed a very low positive relationship existed between students' power narcissism and the two dimensions of self-esteem. A very low negative relationship was recorded between students' exhibitionism narcissism and the dimensions self-esteem. This does not support the study of Donnellan et al (2005)[19] which reveals that self-esteem and narcissism were moderately related. The results from the hypothesis of this revealed that there is a non significant relationship between the 
dimensions of self-esteem and the dimensions narcissism. There is a non significant relationship between students' high self-esteem and their exhibitionism narcissism.

The findings from table five revealed that that the relationship among students' narcissism, self-esteem and academic achievement is very low with the standard error of estimate is high. The result from the hypothesis of testing revealed a non-significant relationship narcissism, self-esteem and academic achievement in mathematics. Therefore, the null hypothesis was rejected it was concluded that the relationship among students' narcissism, self-esteem and academic achievement in mathematics is positively and significantly related with one another.

\section{Conclusion}

The present study had been directed towards studying the relationship of students' narcissism, self-esteem and academic achievement in mathematics. The impact of narcissism, self-esteem and academic achievement in mathematics in relating with one another obviously indicated very low positive and negative relationship among the variables. It is concluded that students' narcissism, and self-esteem does significantly related with academic achievement in mathematics.

\section{Recommendations}

Based on the findings, the following recommendations were made.

1. In other to improve the low positive and negative relationship of these variables, that is, narcissism, and self-esteem on students' academic achievement, the administration of the secondary schools should work on the students' self perception so as to become mentally tough, and also be able to embrace challenges in the academic task.

2. In other to heighten the sense of self-worth and value in the students which will make them more motivated, assertive, and successful in academic context, it is suggested that teachers and significant others will work on students' narcissistic behaviour to become a positive attribute that will have a positive influence on the students' selfesteem.

3. As narcissistic individuals believe strongly that they are better than others, therefore teachers and counsellors should develop a strategy to enhance the confidence and ability in the students as these will help them to become life long learning individuals thereafter.

\section{References}

[1] Miller, J. D., Campbell, W. K. (2008). Comparing clinical and social personality conceptualizations of narcissism. Journal of Personality, 76 (3), 449-476.

[2] Lima, G. A.S.F., Avelino, B. C., \& Cunha, J . V. A. (2018). Narcissism: Are accounting students using their personality trait to perform better? Journal of Accounting and Organizations, 2 (4), 27-29.

[3] Seto, E. (2012). Association between self-reported narcissism, self-esteem and social emotional function of face book. Theses submitted to the faculty of Baylo University. In partial fulfillment of the requirements for the honors programs.

[4] Doty, J., \& Fenlason, J. (2013). Narcissism and toxic leaders. Military Review, 55-60.

[5] Ballard, K. (2018). Is being narcissistic an academic advantage for college students? Undergraduate Student Research Awards. 43

[6] Campbell, W. K., Hoffman, B. J., Campbell, S . M., \& Marchision, G. (2011). Narcissism in organizational context. Human Resources Management Review, 21 (4), 268-284.

[7] Brown, R. P., Budzek, K. \& Tamborski, M. (2009). On the meaning and measure of narcissism. Personality and Social Psychology Bulletin, 35, 951-964.

[8] Campbell, W. K., Bonacci, A. M., Shelton, J., Exline, J. J., \& Bushman, B.J. (2004). Psychological entitlement: Interpersonal consequences and validation of self-report measure. Journal of Personality Assessment, 83 (1), $29-45$.

[9] Hudson, E. J. (2012). Understanding and exploring narcissism: Impact on students and college campuses. CMC Senior Thesis. Paper 381.

[10] Wallace, H. M. \& Baimeister, R.F. (2002). The performance of narcissist rise and falls opportunity for glory. Journal of Personality and Social Psychology, 82 (5) 819-834.

[11] Raskin, R. N., \& Hall, C.S. (1979). A narcissistic personality inventory. Psychological Reports, 45 (2), 570. 
[12] Soyer, R. R., Rovenpor, J. L., Kopelman, Watson, P.J. (2001). Further assessment of the validity of four measures of narcissism: Replication and extension. Journal of Psychology, 135, 245-258.

[13] Baumeister, R. F. (1998). The self. In D. Gilbert, S. Fiske, \& G. Lindzey (Eds.), The handbook of social psychology (pp.680-740). New York: Random House.

[14] (Saadat, M., Ghasezadch, A., \& Soleimani, M. (2012). Self-esteem in Iranian university students in relationship with academic achievement. Procedia Social and Behavioural Sciences, 31, 10-14.

[15] Ghazvini, S. D. (2011). Relationship between academic self-concept and academic performance in high school students in Iran. Procedia Social and Behavioural Sciences, 15, 1034-1039.

[16] Anyamene, A., Nwokolo, C., \& Ezeanni, N. (2016). Effects of assertive training on the low self-esteem of secondary school students' in Anambra State. Journal of Psychology and Behavioural Sciences, 4 (1), 65-78.

[17] Papageorgiou, K.A., Malanchini, M., Denovan, A., Clough, P., Shakeshaft, N., Schofield, K., \& Kovas, Y. (2018). Longitudinal association between narcissism, mental thoughness and school achievement. Personality and Individual Differences, 131, 105-110. https/doi.org/10.1016/j.paid.2018.04.0224.

[18] Zainal, Z.B. (2020). Narcissism behaviour and accounting undergraduate performance in herher learning institution. European Proceedings of Social and Behavioural Sciences, (1). Retrieved from WWW.europeanproceedings.com. Doi:10.15405/epsbs.2020.12.05.21.

[19] Donnellan, M. B., Trzesniewski, K. H., Robins, R. W., Moffitt, T. E., and Caspi, A. (2005). Low self-esteem is related to aggression, antisocial behavior, and delinquency. American Psychological Society, 4, 328-335.

[20] Anyanwu, A. N., \& Emesi, K. E. (2020a). Relationship among secondary school students' academic self-concept, self-esteem and academic achievement in mathematics in Anambra State. Unizik Journal of Educational Research and Policy Studies, 1 (1), $121-122$.

[21] Arshad, M., Zaidi, S. M. I. H., and Mahmood, K. (2015). Self-esteem and academic performance among university students. Journal of Education and Practice, 6(1).

[22] Eleje, L.I., Esomonu, N.P.M., Ufearo, F.N., Anyanwu, A.N., Okoi, O.A., Ugwu, E.O., Emeka, E.A., Ogelle, O.M., \& Eleje, G.U. (2020). Birth by cesarean section and academic achievement in adolescents: A randomized control trial. Obstetrics and Gynaecology Research, 3(4), 251-263. Doi: 10.26502/ogr047

[23] Eleje, L.I., Esomonu, N.P.M., Okoye, R.O., Agu, N.N., Ugorji, C.O., Okoi, O.A., \& Abanobi, C.C. (2020). Students' academic achievement in secondary-school quantitative economics: Effect of feedback with remediation. The Asian Institute of Research Education Quarterly Reviews, 3(4), 479-488. DOI: 10.31014/aior.1993.03.04.155

[24] Masten, A. S., Rosiman, G. I., Long, J. D., Burt, K. B., Obradovic, J., \& Riley, J.R. (2005). Developmental cascades: Linking academic achievement and externalizing and internalizing symptoms over 20 years. Developmental Psychology, 41, 733-746.

[25] Eysenck, H. J., \& Eysenck, S. B. G. (1976). Psychoticism as a dimension of personality. London: Hodder \& Stoughton.

[26] Haradhan, M. (2017). Two criteria for good measurements in research: Validity and reliability. Annals of Spiru Haret University, 17(3), 58-82.

[27] Okoye, R. (2015). Educational and psychological measurement and evaluation (second edition ): Awka, Erudition Publisher.

[28] Anyanwu, A. N., \& Emesi, K. E. (2020b). Secondary school students' self-esteem and achievement goal orientation as correlates of academic achievement in mathematics in Anambra state. International Journal of Multidisciplinary and Current Educational Research, 2, (5) 218-226. 